\title{
Inhibition of Yeast in Commercial Pickle Brines
}

\author{
T. Doan ${ }^{1}$, D. Babu ${ }^{1} \&$ R. Buescher ${ }^{1}$ \\ ${ }^{1}$ Department of Food Science, University of Arkansas, Fayetteville, AR, USA \\ Correspondence: Ron Buescher, 2650 North Young Ave, Food Science Department, University of Arkansas, \\ Fayetteville, AR 72701, USA. Tel: 1-479-575-4775. E-mail: buescher@uark.edu
}

Received: June 6, 2012 Accepted: July 12, 2012 Online Published: July 27, 2012

doi:10.5539/jfr.v1n3p295 URL: http://dx.doi.org/10.5539/jfr.v1n3p295

\begin{abstract}
This study investigated the inhibition of yeasts in brines from fermented cucumber pickles using 2, 4-hexadienoic (sorbic), hexanoic and (E)-3-hexenoic acids. Native yeast population and chemical composition of commercial brines were analyzed and the minimum inhibitory concentrations of inhibitors on yeast growth were established. Commercial brines were treated with 100-350 ppm of 2, 4-hexadienoic (sorbic), hexanoic and (E)-3-hexenoic acids individually and at 2.5 to $10 \%$ salt (sodium chloride) concentrations. Yeast populations in the treated brines were monitored for 30 days of incubation. Hexanoic and (E)-3-hexenoic acids at $350 \mathrm{ppm}$ caused reduction in yeast populations by about 4 and $2 \log$ CFU/ml, respectively, within 24 hours of treatment. However, when brines were treated with 2, 4-hexadienoic acid at salt concentrations of 7.5 to $10 \%$, there were no significant differences noted in yeast inhibition between the three acids. Hexanoic and (E)-3-hexenoic acids at $200 \mathrm{ppm}$ caused longer lasting inhibitory effects (30 days) on yeasts than the traditionally used 2, 4-hexadienoic acid (10 days) in fermentation brine. Thus, the hexanoic and (E)-3-hexenoic acids are potential alternatives to 2 , 4-hexadienoic acid for controlling yeasts during storage of spent cucumber fermentation brines.
\end{abstract}

Keywords: yeast inhibition, cucumber pickle brine, 2, 4-hexadienoic acid, hexanoic acid, hexenoic acid

\section{Introduction}

Commercial fermentation of cucumbers is mainly done in open tanks filled with freshly prepared or recycled brine solution containing 6-8\% sodium chloride. The salt in brine solutions helps to preserve firmness of the fruits, prevent growth of spoilage bacteria and select homo-fermentative lactic acid bacteria. (Fleming, 1982). However, certain yeasts such as Hansenula, Torulopsis, Saccharomyces, Candida, Debaromyces, and Rhodotorula can grow in the spent brines and drastically affect the quality of cucumber pickles (Etchells, Costilow, Bell, \& Rutherfords, 1961). Other yeasts such as the film forming Pichia anomala are also reported in pickled vegetables (Hung \& Kyung, 2006; Pitt \& Hocking, 2009). Although commonly used salt concentrations can selectively promote lactic acid bacterial growth (Etchells \& Jones 1943), they may not affect the survival of salt tolerant yeasts. Failure to inhibit growth of yeasts, molds, certain bacteria and their enzymes in brines can affect the color, flavor and texture of the pickled product wherein the growth of yeasts in cucumber fermentation tanks can specifically reduce lactic acid, increase brine $\mathrm{pH}$, and increase carbon dioxide production leading to bloater formation (Jones, Etchells, Veerhoff, \& Veldhuis, 1941). Although the problem of yeast growth in commercial fermentation tanks is typically addressed by adding 2, 4-hexadienoic (sorbic) acid (Costilow, Ferguson, \& Ray, 1955; Costilow, Coughlin, Robbins, \& Hsu, 1957), the preservative effect of this compound is usually temporary because of its susceptibility to microbial degradation causing more than $50 \%$ loss of the added amounts within a month (Gordon \& Lewis 1958). This degradation of 2, 4-hexadienoic acid is also known to be influenced by exposure to sunlight since fermentation tanks are left open to reduce the growth of surface yeasts during fermentation and bulk storage (Saxby, Stephens, \& Reid, 1982). Thus, alternatives to sorbic acid need to be evaluated for their efficacy to inhibit growth of yeast in cucumber fermentation brines.

Majority of natural flavoring agents are also known to contain broad range of compounds imparting antimicrobial properties against different food pathogenic and spoilage causing microorganisms including Campylobacter jejuni, Escherichia coli, Listeria monocytogenes, and Salmonella enterica and yeasts such as $S$. cerevisiae, Candida albicans, Debaryomyces hansenii (Friedman, Henika, \& Mandrell, 2002; Suppakul, Sonneveld, Bigger, \& Miltz 2008; Gutiérrez, Escudero, Batlle, \& Nerín, 2009; Kuorwel, Cran, Sonneveld, Miltz, \& Bigger, 2011). The yeast inhibiting properties of many flavoring agents or essential oils can be attributed to their natural components such as eugenol present in oils of many spice, cinnamon leaf, clove bud and leaf, and 
cinnamamic aldehydes present in cinnamon bark oil, cassia oil (Kuorwel et al., 2011). These compounds are also known for their antimicrobial properties in acid foods (Jay \& Rivers, 1984) indicating their use as preservatives in cucumber fermentation brines. However, the essential oil components to be used for preservation of cucumber pickle should be effective under high salt concentrations of the fermentation brines. Due to the vast number of existing natural or chemical preservatives, the selection of a natural compound inhibiting yeast in high salt containing cucumber fermentation brines can be done by confirming their lasting effectiveness and structural similarity to existing stable compounds. Hexanoic and (E)-3-hexenoic acid are natural flavoring agents and are expected to be more stable and effective as they have no or one double bond respectively when compared to the two double bond containing 2, 4-hexadienoic acid. Furthermore, these compounds are considered as weak acid preservatives that are effective at acidic $\mathrm{pH}$ (Eklund, 1980) and lesser double bonds of these compounds could make them more stable than sorbic acid. Thus, the objectives of this study were to evaluate inhibition of yeast growth in commercial spent cucumber fermentation brines using hexanoic, (E)-3-hexenoic and 2, 4-hexadienoic acids and also to compare their effectiveness at different salt concentrations.

\section{Method}

\subsection{Preparation of Spent Brines and Test Compounds}

Spent brines were obtained from commercial pickle manufacturers. Test compounds for inhibition of yeast growth in commercial spent brine were obtained from Sigma-Aldrich Chemical Company supplied at $99.9 \%$ purity by the manufacturer. Hexanoic and (E)-3-hexenoic acids that were insoluble in water were emulsified before use by sonicating with Tween-20 at $1 / 0.5$ ratio and by gradually adding deionized water while sonicating. The final volume of emulsion was adjusted to $100 \mathrm{ml}$ by slowly adding deionized water. Total sonicating time varied from 1 to 2 hours depending on each chemical and each emulsion was used immediately for subsequent study. Different concentrations $(0,25,50,100,200,300$, and $400 \mathrm{ppm})$ of the oil emulsion were prepared in 100 $\mathrm{ml}$ of commercial recycled brine using a $20,000 \mathrm{ppm}$ stock solution for each chemical, thus even the highest concentration of $400 \mathrm{ppm}$ used in treatments did not have a major dilution on the brine samples. The samples were placed in disposable plastic cups and lightly covered by plastic Petri dishes to prevent evaporation. The test samples were incubated in dark at $25 \pm 2{ }^{\circ} \mathrm{C}$ for 30 days.

\subsection{Chemical Analysis of Recycled Brines}

Spent brines were assayed for $\mathrm{NaCl}$, titratable acidity, $\mathrm{pH}$ and calcium as previously described (Buescher \& Burgin, 1988). Sorbic acid content in the spent brines was measured by a modified protocol of Ziemelis and Somers, (1978) as previously described by Buescher and Hamilton (2000).

\subsection{Yeast Enumeration from Brine Samples}

Yeast populations of the brine samples were estimated by dilution plating wherein the recycled brine was serially diluted in sterile $0.1 \%$ buffered peptone water (Difco Co., Detroit, MI) and $1 \mathrm{ml}$ of each dilution was plated on yeast and mold (YM) Petrifilms (3M Co., St. Paul, MN). The plates were incubated for 5 days at $25 \pm 2{ }^{\circ} \mathrm{C}$. Plating and counting techniques were done as described in YM petrfilm brochure. Surface yeast was determined by the appearance of white film on surface of brine. Confirmation of yeast cells was made by observation of the film layer suspension prepared in $0.1 \%$ buffered peptone water under microscope using $40 \mathrm{X}$ magnification. Enumeration of initial yeast population in recycled brine was done before each test and necessary adjustment of yeast population was needed to be done for some brine obtained from processing companies as the population of yeast varied from tank to tank.

\subsection{Inhibition of Yeast Growth by Hexanoic, (E)-3-hexenoic, and 2, 4-hexadienoic Acids}

Yeast inhibition by use of hexanoic, (E)-3-hexenoic, and 2, 4-hexadienoic (sorbic) acids was compared at 350 ppm concentration of each compound prepared in $100 \mathrm{ml}$ of recycled brine. Untreated recycled brine samples were used as control. For each treatment, viable yeast population was measured at 0,24 , and $48 \mathrm{~h}$. Time of film yeast appearance on the surface of brine was recorded during the 30-day observation period. Another set of treatments was established the same way as described above except that the initial yeast population in the brine was $10^{5} \mathrm{CFU} / \mathrm{ml}$ and concentrations from 0 to $350 \mathrm{ppm}$ of each chemical were tested for yeast inhibition.

\subsection{Influence of Sodium Chloride on Yeast Inhibition by Hexanoic, (E)-3-hexenoic, and Sorbic Acids}

A commercial recycled brine sample was diluted using deionized water to contain $2.5 \% \mathrm{NaCl}$, and then adjusted to $\mathrm{NaCl}$ concentrations to $5,7.5$, and $10 \%$. This was done to start with same base brine solution for the experiment on testing the effectiveness of Hexanoic, (E)-3-hexenoic or 2, 4-hexadienoic acid (each at $350 \mathrm{ppm}$ ) under different salt concentrations. In addition, $\mathrm{pH}$ was adjusted to 3.3 in all treatments using $\mathrm{HCl}$. The time for film yeast first appearance on the brine surface and viable yeast population were recorded. 


\subsection{Statistical Analysis}

The values of $\log \mathrm{CFU} / \mathrm{ml}$ of yeast populations and the days of appearance averaged from three independent replications were subjected to one way analysis of variance (ANOVA) by Statistical Analysis Software (SAS 9.2, SAS Institute Inc. Cary, NC), and mean comparisons were done using Tukeys significance grouping where $\mathrm{p}$ values of $<0.05$ were considered statistically significant. Data plotting was done using SigmaPlot 12.0 (Systat Software, Inc., San Jose, CA)

\section{Results and Discussion}

The commercial spent brines used for yeast inhibition experiments contained $8.8 \%$ to $9.4 \% \mathrm{NaCl}$ with $\mathrm{pH}$ of $3.30-3.50$, and $0.69 \%$ to $0.77 \%$ lactic acid. The native yeast population of the spent brine was $10^{4}$ to $10^{5} \mathrm{CFU} / \mathrm{ml}$ and when the yeast population was found to be lower than this level, the brine was incubated at $25^{\circ} \mathrm{C}$ until it reached at least $10^{4} \mathrm{CFU} / \mathrm{ml}$. Although the identification of yeast species was beyond the scope of this study, the growth pattern and colony types were found to be similar when plated on YM plates and as determined using a microscope at 40X magnification.

The effects of hexanoic acid, (E)-3-hexenoic acid, and 2, 4-hexadienoic acid on inhibition of film yeast growth in cucumber recycled brine was tested. Even though these acids were described as unpleasant flavors (Fenaroli, 2002), they did not cause an objectionable odor in recycled brine at concentrations as high as $350 \mathrm{ppm}$. The minimum inhibitory concentrations (MIC) for yeast inhibition by hexanoic acid and hexenoic were 200 and 350 ppm, respectively, and they prevented film yeast growth for more than 30 days at $200 \mathrm{ppm}$, whereas same amount of sorbic acid prevented film yeast for only 10 days (Table 1). In the control brine where no inhibitor was added, film yeast growth occurred within 2 days.

Table 1. Effect of hexanoic, hexenoic, and 2, 4-hexadienoic (sorbic) acid concentrations on inhibition of yeast in spent cucumber fermentation brine

\begin{tabular}{lccccccc}
\hline & \multicolumn{8}{c}{ Time (days) for appearance of yeast } \\
\cline { 2 - 8 } \multicolumn{1}{r}{ Treatment } & 0 & 25 & 50 & 100 & 200 & 300 & 350 \\
\hline Control & 2 & - & - & - & - & - & - \\
Hexanoic acid & - & - & - & - & $>30$ & $>30$ & $>30$ \\
Hexenoic acid & - & 2 & 3 & 4 & $>30$ & $>30$ & $>30$ \\
2,4-hexadienoic acid & - & 2 & 2 & 3 & 10 & $>30$ & $>30$ \\
\hline
\end{tabular}

Before identifying the optimum concentrations of hexanoic acid, (E)-3-hexenoic acid and 2, 4-hexadienoic acids on the yeast population in commercial recycled brine, the chemicals were first tested at $350 \mathrm{ppm}$ concentration against a known yeast population. A brine solution containing $4.5 \mathrm{log} \mathrm{CFU} / \mathrm{ml}$ of yeast population with similar $\mathrm{pH}, \mathrm{NaCl}$, and lactic acid concentration was used for this study along with a control brine without any of the added inhibitory compounds. The results indicated that, within 24 hours of application, hexanoic acid was the most effective among the three test chemicals reducing the yeast population by about $3.5 \mathrm{Logs} \mathrm{CFU} / \mathrm{ml}$, whereas (E)-3-hexenoic acid and sorbic acid showed reduction by 1 and less than $1 \log \mathrm{CFU} / \mathrm{ml}$ respectively (Figure 1). After 48 hours of treatment, yeast population in the brine samples treated with the three acids were significantly less $(p<0.05)$ in comparison to the control samples. Further, identification of optimum inhibitory concentrations of hexanoic, (E)-3-hexenoic, and sorbic acid on growth of film yeast and yeast population was done using 100-350 ppm concentrations of the compounds in the recycled brines that were adjusted to contain initial yeast population of $7.3 \times 10^{5} \mathrm{CFU} / \mathrm{ml}$. As shown in Figures 2 (A), 2 (B) and 2 (C), the yeast inhibition by adding 100 $\mathrm{ppm}$ of hexanoic, and (E)-3-hexenoic acids did not differ significantly with the control $(\mathrm{p}<0.05)$. At about 200 ppm, hexanoic acid and sorbic acid reduced the yeast population after 2 days of treatment to $10 \mathrm{CFU} / \mathrm{ml}$ and continued to suppress the number of yeasts for the following days. On the other hand, $200 \mathrm{ppm}$ (E)-3-hexenoic acid was not effective in reducing the number of yeast, but it effectively prevented yeast from developing. At 350 ppm, hexanoic acid reduced the yeast population by $3 \log \mathrm{CFU} / \mathrm{ml}$ within 2 days, while (E)-3-hexenoic acid and sorbic acid reduced $2 \log \mathrm{CFU} / \mathrm{ml}$. Sorbic acid continued to reduce the yeast population by 2 more $\log \mathrm{CFU} / \mathrm{ml}$ in the following 2 days, while hexanoic acid and (E)-3-hexenoic acid did not further reduce the number of yeasts. 


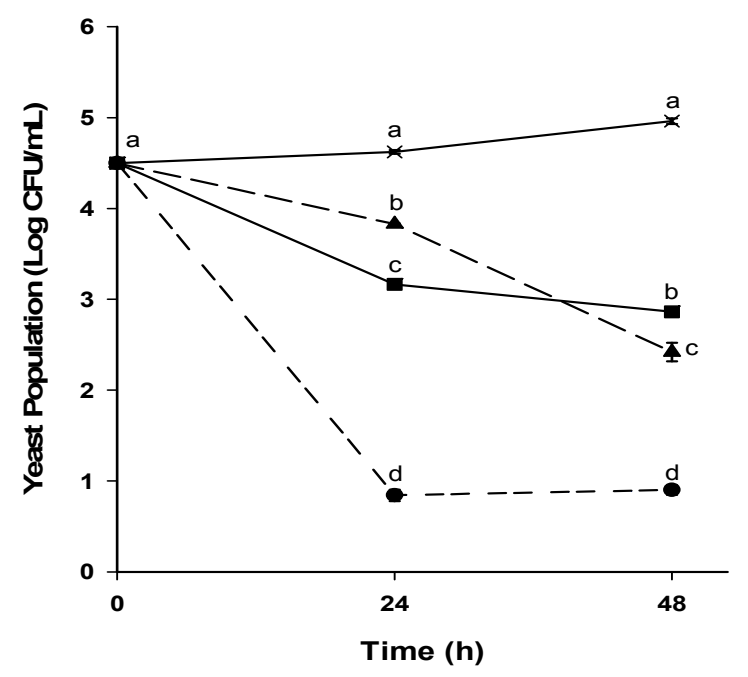

Figure 1. Inhibition of indigenous yeast in commercial spent brine by $350 \mathrm{ppm}$ hexanoic acid, (E)-3-hexenoic acid, or 2, 4-hexadienoic acid. The brine contained $8.83 \% \mathrm{NaCl}, 3.34 \mathrm{pH}, 0.77 \%$ lactic acid and initial yeast population of $4.8 \times 10^{4} \mathrm{CFU} / \mathrm{ml}$. The mean values at each time of measurement labeled with different letters

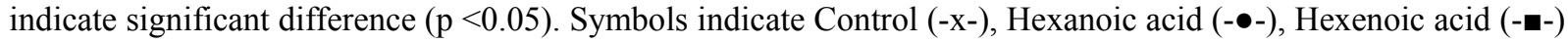
and 2, 4-hexadienoic acid (- $\mathbf{\Delta - )}$
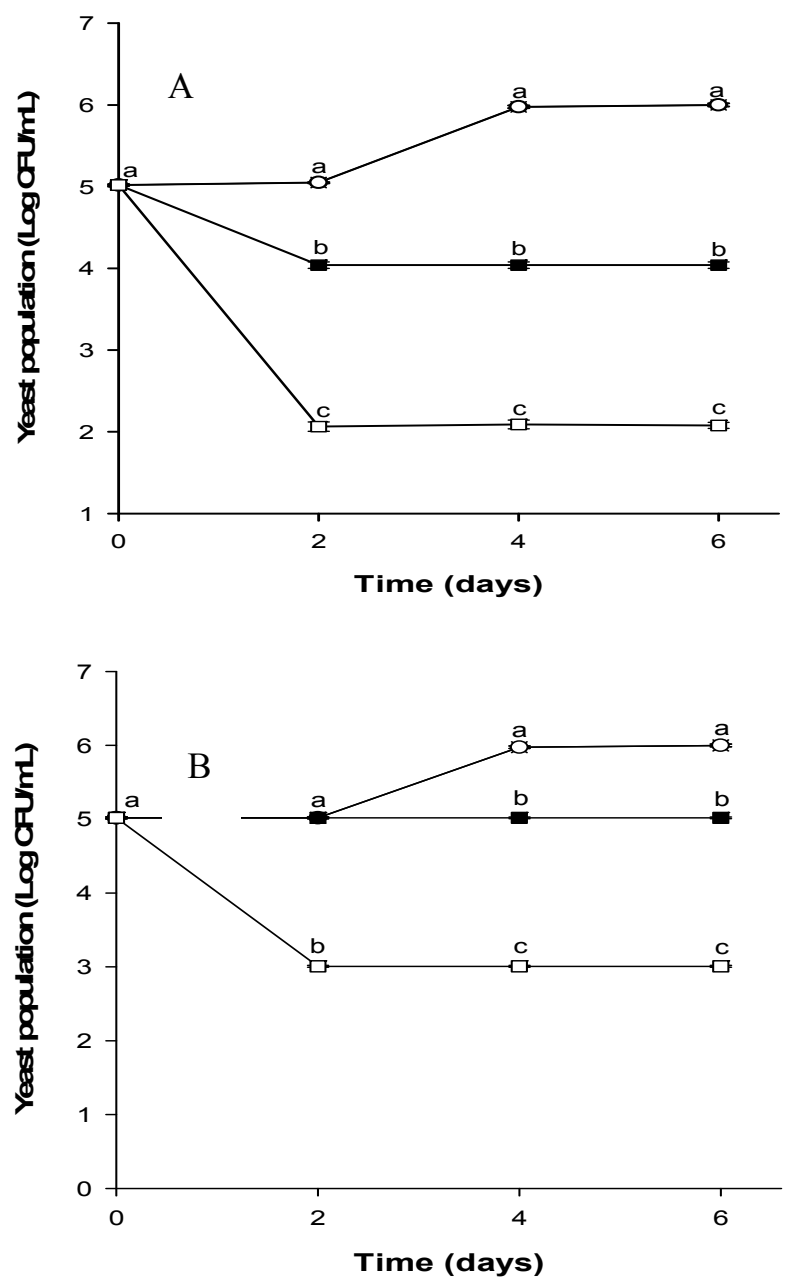


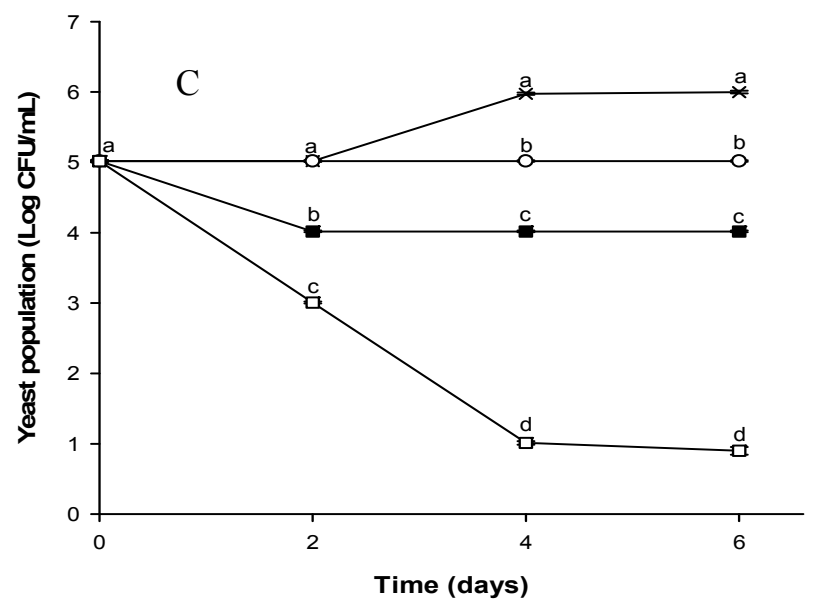

Figure 2. Inhibition of yeast population in commercial brines added with hexanoic acid (A), (E)-3-hexenoic acid (B), and 2,4-hexadienoic acid (C) at 100-350 ppm concentrations. Initial yeast count in the brine was at $7.3 \times 10^{5}$

$\mathrm{CFU} / \mathrm{ml}$, with $8.9 \% \mathrm{NaCl}$ and $3.3 \mathrm{pH}$. The mean values at each day of measurement with different letters indicate significantly difference ( $\mathrm{p}<0.05)$. Symbols indicate Control (-x-), 100ppm (-o-), 200ppm (-m-) and

300ppm (-口-)

The effects of sodium chloride concentration on yeast inhibition by hexanoic, (E)-3-hexenoic and sorbic acids in commercial recycled brine was also tested. Although sodium chloride is added as preservative in spent brine, addition of $\mathrm{NaCl}$ alone at concentrations of less than $7 \%$ may not be effective for yeast inhibition (Yang \& Buescher, 2000). Furthermore, even at concentration as high as $20 \%, \mathrm{NaCl}$ alone may not be very effective in inhibition on most of the fungi (Kurita \& Koike, 1982) in brine solutions. Thus, the effect of $\mathrm{NaCl}$ concentration on yeast population of brine treated with $350 \mathrm{ppm}$ of hexanoic acid, (E)-3-hexenoic acid, or sorbic acid was examined to test their efficacy in commercial brine (Figure 3). Hexanoic acid and sorbic acid both inhibited yeast growth for more than 30 days in brine containing $5,7.5$, and $10 \% \mathrm{NaCl}$ and differed significantly with control $(\mathrm{p}<0.05)$. However, $\mathrm{NaCl}$ at a concentration of $2.5 \%$ failed to exhibit any observable anti-yeast effect with any of the chemical treatments or control. Results indicated that $350 \mathrm{ppm}$ of inhibitors effectively inhibited yeast growth in samples containing $5 \%$ or more $\mathrm{NaCl}$. The anti-yeast effect of these chemicals in brine with $2.5 \%$ $\mathrm{NaCl}$ was substantially less than that in $5 \%$ or more $\mathrm{NaCl}$. Apparently, $\mathrm{NaCl}$ at concentration of $5 \%$ or more substantially increased effect of hexanoic, (E)-3-hexenoic, and sorbic acid in yeast growth inhibition.

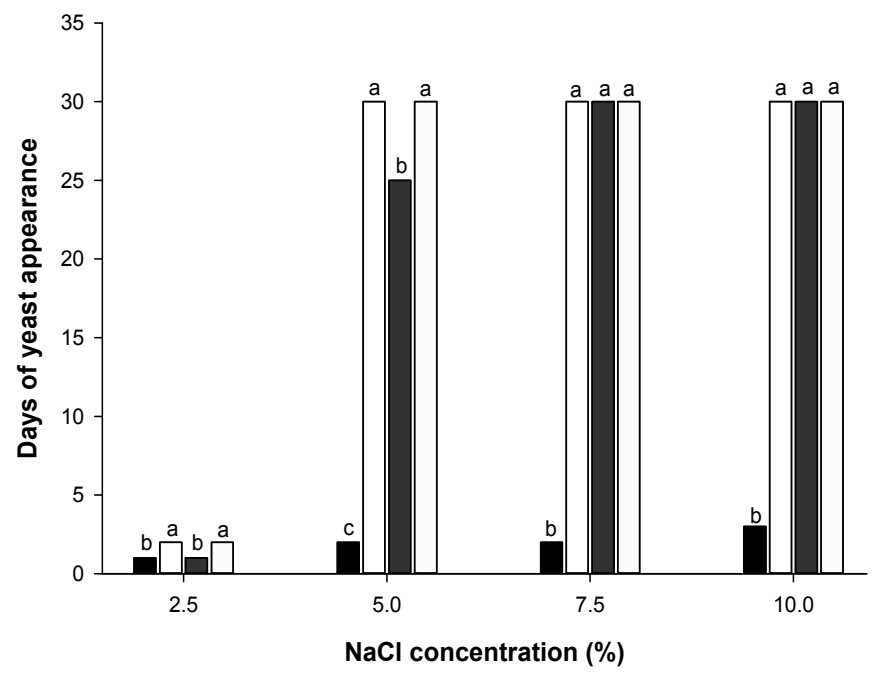

Figure 3. Effect of $\mathrm{NaCl}$ concentrations in spent cucumber fermentation brine on yeast inhibition by control (no

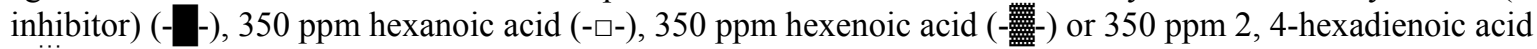
(-) at $\mathrm{pH} 3.3$ and $25 \pm 2^{\circ} \mathrm{C}$ incubation temperature. The mean values of days for appearance of yeast at each

$\mathrm{NaCl}$ concentration with different letters indicate significant difference $(\mathrm{p}<0.05)$ 


\section{Conclusions}

Yeasts were abundant in commercial spent cucumber fermentation brines and increased in number unless treated with hexanoic, hexenoic or 2, 4-hexadienoic (sorbic) acids. Brines containing $200 \mathrm{ppm}$ of either of the acids prevented yeast growth and at $350 \mathrm{ppm}$ they substantially reduced the yeast population. Inhibition by the acids was minor in brine containing $2.5 \% \mathrm{NaCl}$, but very effective when the $\mathrm{NaCl}$ concentration was $5 \%$ or higher. It appears that hexanoic or hexenoic could be used instead of sorbic acid to prevent yeast growth during storage of spent cucumber fermentation brine.

\section{Acknowledgements}

This study was supported by the University of Arkansas, Division of Agriculture, Agricultural Experiment Station Fayetteville, AR, and Pickle Packers International, Inc.,U.S.A.

\section{References}

Buescher, R., \& Hamilton, C. (2000). Protection of cucumber pickle quality by $\mathrm{CaNa}_{2}$ EDTA. Journal of Food Quality, 23, 429-441. http://dx.doi.org/10.1111/j.1745-4557.2000.tb00569.x

Buescher, R. W., \& Burgin, C. (1988). Effect of calcium chloride and alum on fermentation, desalting, and firmness retention of cucumber pickles. Journal of Food Science, 53, 296-297. http://dx.doi.org/10.1111/j.1365-2621.1988.tb10238.x

Costilow, R. N., Coughlin, F. M., Robbins, E. K., \& Hsu, Wen-Tah. (1957). Sorbic acid as a selective agent in cucumber fermentations. II. Effect of sorbic acid on the yeast and lactic acid fermentations in brined cucumbers. Applied Microbiology, 5, 373-379. http://aem.asm.org/content/5/6/373.citation

Costilow, R. N., Ferguson, W. E., \& Ray, S. (1955). Sorbic acid as a selective agent in cucumber fermentations. I. Effect of sorbic acid on microorganisms associated with cucumber fermentations. Applied Microbiology, 3, 341-345. http://aem.asm.org/content/3/6/341.citation

Eklund, T. (1980). Inhibition of growth and uptake processes in bacteria by some chemical food preservatives. Journal of Applied Bacteriology, 48, 423-432. http://dx.doi.org/10.1111/j.1365-2672.1980.tb01031.x

Etchells, J. L., \& Jones, I. D. (1943). Bacteriological changes in cucumber fermentation. Food Industries, 15, 54-56. http://ncsu.edu/foodscience/USDAARS/Acrobatpubs/P1-29/P18.pdf

Etchells, J. L., Costilow, R. N., Bell, T. A., \& Rutherfords, H. A. (1961). Influence of gamma radiation on the microflora of cucumber fruit and blossoms. Applied Microbiology, 9, 145-149. http://www.ncbi.nlm.nih.gov/pmc/articles/PMC1057692/pdf/applmicro00334-0057.pdf

Fenaroli, G. (2002). Fenaroli's Handbook of Flavor Ingredients. 745-746. Boca Raton, USA: CRC Press.

Fleming, H. P. (1982). Fermented vegetables. In Rose, A.H. (Ed.), Economic Microbiology: Fermented Foods, 7 , 227-258. New York, NY: Academic Press.

Friedman, M., Henika, P. R., \& Mandrell, R. E. (2002). Bactericidal activities of plant essential oils and some of their isolated constituents against Campylobacter jejuni, Escherichia coli, Listeria monocytogenes, and Salmonella enterica. Journal of Food Protection, 65, 1545-1560. http://www.ncbi.nlm.nih.gov/pubmed/12380738

Gordon, G. L., \& Lewis, J. C. (1958). Determination of sorbic acid and its disappearance from pickle brines. Food Research, 23, 338-344. http://dx.doi.org/10.1111/j.1365-2621.1958.tb17578.x

Gutiérrez, L., Escudero, A., Batlle, R., \& Nerín C. (2009). Effect of mixed antimicrobial agents and flavors in active packaging films. Journal of Agricultural and Food Chemistry, 57, 8564-8571. http://dx.doi.org/10.1021/jf901459e

Hung, Le-Dinh, \& Kyung, K. H. (2006). Inhibition of yeast film formation in fermented vegetables by materials derived from garlic using cucumber pickle fermentation as model system. Food Science and Biotechnology, 15, 469-473. http://agris.fao.org/aos/records/KR2007000433

Jay, J. M., \& Rivers, G. M. (1984). Antimicrobial Activity of Some Food Flavoring Compounds. Journal of Food Safety, 6, 129-139. http://dx.doi.org/10.1111/j.1745-4565.1984.tb00609.x

Jones, I. D., Etchells, J. L., Veerhoff, O, \& Veldhuis, M. K. (1941). Observations and bloater formation in cucumber fermentation. The Fruit Products Journal, 20, 202-216.

Kuorwel, K. K., Cran, M. J., Sonneveld, K., Miltz, J., \& Bigger, S. W. (2011). Antimicrobial activity of natural agents against Saccharomyces cerevisiae. Packaging Technology and Science, 24, 299-307. 
http://dx.doi.org/10.1002/pts.939

Kurita, N., \& Koike, S. (1982). Synergistic antimicrobial effect of sodium chloride and essential oil components. Agricultural and Biological Chemistry, 46, 159-165.

Pitt, J. I., \& Hocking, A. D. (2009). Primary Keys and Miscellaneous Fungi. In Pitt, J. I. \& Hocking, A.D. (Eds.), Fungi and Food Spoilage, 122-124, 375-376. New York, NY: Springer.

Saxby, M. J., Stephens, M. A., \& Reid, R. G. (1982). Degradation of sorbic acid in model food systems. Food Chemistry, 9, 283-287. http://dx.doi.org/10.1016/0308-8146(82)90079-6

Suppakul, P., Sonneveld, K., Bigger, S. W., \& Miltz, J. (2008). Efficacy of polyethylene-based antimicrobial films containing principal constituents of basil. LWT-Food Science and Technology, 41, 779-88. http://dx.doi.org/10.1016/j.1wt.2007.06.006

Yang, R., \& Buescher, R. (2000). Factors Affecting Cucumber Flavor Production, Stability and Yeast Inhibition by Cucumber Flavor Volatiles: Trans-2-nonenal and Trans-2-cis-6-nonadienal. M.S. Thesis. Department of Food Science, University of Arkansas, Fayetteville, AR.

Ziemelis, G., \& Somers, T. C. (1978). Rapid determination of sorbic acid in wine. American Journal of Enology and Viticulture, 29, 217-219. 